23 Shah D, Azhar M, Oakley CM, Cleland JGF, Nihoyannopoulos P. Natural history of secundum atrial septal defect in adults after medical or surgical treatment: a historical prospective study. Br Heart $\mathcal{F}$ 1994; 71: 224-8.

24 Konstantinides S, Geibel A, Olschewski M, et al. A comparison of surgical and medical therapy for atrial septal defect in adults. N Engl f Med 1995; 333: 469-73.

25 Foster-Smith KW, Murphy JG, Bailey KR, et al. Secundum atrial septal defect (ASD): clinical profile and surgical experience in septuagenarians and older. Proceedings of the American College of Cardiology Meeting. Atlanta, Georgia, 1994; 465A: 826-32.
26 Ueda K. Clinical profiles, pathologic spectrum and management of atrial septal defect in patients aged 50 or over: how should they be treated? $f$ Cardiogr 1984; 14: 129-36.

27 Konstantinides S, Geibel A, Kasper W, et al. The natural course of atrial septal defect in adults-a still unsettled issue. Klin Wochenschr 1991; 69: 506-10.

28 Ward C. Secundum atrial septal defect: routine surgical treatment is not of proven benefit. Br Heart $¥$ 1994; 71 : 219-23.

\title{
Cystic fibrosis in teenagers and young adults
}

The millennium will see over 6000 patients with cystic fibrosis in the UK, half of whom will be teenagers and adults, the over 15 age group increasing by about 120 per year. ${ }^{1}$ We are not providing sufficient resources for this latter group now, nor are we making sufficient commitment to their future needs. There are three reasons for this. Firstly, some fault rests with the apparent failure of the NHS hospital trusts' management to deploy income derived from purchaser provision for cystic fibrosis care back into the cystic fibrosis service. There is also their persistent failure to meet the staffing levels recommended for cystic fibrosis centres by the British Paediatric Association (BPA), the British Thoracic Society, the Cystic Fibrosis Trust, ${ }^{2}$ and the Royal College of Physicians ${ }^{3}$ and their alleged failure to have established a realistic cost for treatments. Secondly, there are a significant minority of professional colleagues who refuse to refer older patients with this multisystem disease to cystic fibrosis centres with appropriate multidisciplinary teams. Finally, some fault also rests with those of us who have a major commitment to cystic fibrosis care failing to initiate a proper training programme with recognised accreditation for junior doctors wishing to care for patients with cystic fibrosis.

\section{Special needs of the teenage patient with cystic} fibrosis: the 'transitional' clinic

Inevitably close ties develop between the paediatric medical and nursing teams and the patients and their families. Important though these are in giving the child and family emotional security, they must be loosened and eventually broken to allow the patient to grow into independence, and realise responsibility for self. Teenagers with cystic fibrosis can only grow into adulthood in an environment designed to cultivate their independence. Close collaboration between paediatric and adult cystic fibrosis teams is essential so that a system of care is established within which the patient's transition through the turbulence of adolescence is as smooth as possible. In Leeds we believe that this is best achieved in a flexible 'transitional' clinic, run by staff from both the paediatric and adult teams. Patients usually transfer from paediatric to transitional clinic at about 14 years of age, and from transitional to adult clinic, according to individual needs, between 16 and 18 years of age. A survey of our own patients showed that knowledge of the transitional clinic had reduced patients' anxieties about leaving the paediatric unit, and getting to know the adult carers, before moving on to the adult clinic proper, had reassured them. ${ }^{4}$

\section{Cystic fibrosis centres for young adults}

The teenager with cystic fibrosis must be allowed to leave the paediatric unit and the paediatrician behind. There is no justification for the paediatrician retaining the reins of care either because of the spurious excuse that no adult respiratory specialist will give the level of commitment required, or to maintain 'patient numbers' in the NHS market economy. Nor should 'adult' clinics run by a paediatrician and chest physician be seen as fulfilling a need outside of the transitional clinic referred to above. The paediatrician has to 'let go'. But responsibility for continuing care must involve an adult cystic fibrosis centre. If, as paediatricians, we accept the argument for centred care for children with cystic fibrosis, then similarly we must accept centred care for adult patients.

Some with responsibility for older patients with cystic fibrosis believe that all of them should receive total care at the cystic fibrosis centre. Why? Because cystic fibrosis is a multisystem, complex disease and, with present high standards of care in paediatric centres, multisystem complications are often confined to adults. Hence, not only must a critical mass of experience be learned so that one is alerted to complications early, but colleagues in many disciplines (for example obstetrics and gynaecology, endocrinology, rheumatology, gastroenterology, surgery), must become familiar with the problems presented in their own fields by adult patients with cystic fibrosis. A sufficient patient 'through-put' can take place only in a cystic fibrosis centre. Access to specialist paramedical personnel and to basic, not esoteric, investigations is significantly easier within specialist clinics. ${ }^{5}$ Patients cared for by cystic fibrosis specialist staff receive more intensive treatment, especially with regard to nutrition, and are significantly more likely to adhere to physiotherapy regimens and to be self reliant. Physicians who believe that they can offer optimal care by looking after a few patients with a physiotherapist, dietitian, and social worker unschooled in the special needs of cystic fibrosis, are wrong. Units which believe that they can offer a safe and optimal home based intravenous antibiotic treatment programme without a cystic fibrosis liaison nurse are wrong. Young adult patients have voiced clearly their concerns about the fall in quality service they have experienced on transfer from specialist paediatric cystic fibrosis units to general adult chest clinics. ${ }^{5}$

There has been a marked increase over the last five years in the numbers of older patients attending specialist clinics. Seventy seven per cent now receive full or shared care from a cystic fibrosis centre. Ninety eight per cent want some input to their care from a specialist centre and $96 \%$ of patients not currently receiving centre care would prefer it if they were. ${ }^{5}$ Existing centres must be properly resourced to cope with these rapidly increasing numbers, and new centres set up in areas of need.

\section{What an adult centre must offer}

First and foremost the centre must be adequately staffed and have access to adequate bed numbers, preferably on a dedicated cystic fibrosis ward. It is unlikely that anyone other than a full time cystic fibrosis physician will be able to care properly for more than 100 patients. Therefore most large units will require two consultants. Teenagers and adults should have easy access to significant amounts of their doctor's time. Issues such as career choices, life 
expectancy, problems of pregnancy and lung transplant, cannot be properly discussed at outpatient appointments or during bedside 'chats' within the ward round. Certainly junior doctors must be trained in the complexities of adult cystic fibrosis medicine, but patients cannot be expected to relate intimately and repetitively to a succession of short term staff who may know less about their disease than they do themselves. ${ }^{5}$ Units would be ideally served in addition by a permanent staff grade post.

Only those unacquainted with the myriad problems of cystic fibrosis in an aging patient group would dare to assume ultimate responsibility for their wellbeing without the expert support of a physiotherapist, dietitian, social worker, pharmacist and nursing staff, all with experience of cystic fibrosis in their own field. More such professionals are needed now and this need will increase commensurate with the predicted expansion in the patient population. We should be working in concert with each of these disciplines to ensure that proper numbers of staff are being trained.

What is a realistic bed need? It is clear from first hand experience that the four beds per 50 patients suggested by the BPA, ${ }^{6}$ and taken up by other authorities, is insufficient for an adult clinic. In 1994 almost one quarter of patients were refused admission because no bed was available compared with $13 \%$ of patients in $1990 .^{5}$ We are not responding to this worsening situation. Many patients need two to three monthly courses of intravenous antibiotic treatment. Some on the transplant waiting list will spend one to two weeks a month in hospital. Long and cold winters will further stretch resources. In our own unit in January of this year we regularly had 10-15 patients on a waiting list for admission.

Most specialists in cystic fibrosis in the UK would only use intensive care facilities for patients with an acute and reversible crisis. None the less, if we are to treat our patients properly we do need to be equipped properly with pulse oximeters, infusion pumps, syringe pumps, nasal intermittent positive pressure ventilators, and computerised records. Hospital trusts must assume some responsibility for this basic equipment, which at present is funded almost entirely from charitable donations.

We must never forget, either in times of enthusiasm for new treatments or in times of despair at the daily battle to achieve a proper level of support, that cystic fibrosis despite the major recent advances, takes a serious toll of patients' time. The cystic fibrosis centre should aim to minimise the disturbing intrusions of hospital admissions into patients' lives by offering a 'home' environment; individual rooms with televisions, video recorders, fridges, and wardrobe space; dayrooms with entertainment facilities; easy entry to the kitchen and good cooking facilities including a microwave oven; washing and drying machines; opportunities for self medication; a system that allows 'time out' from the ward as long as treatment is not missed.

\section{Reasonable expectations for a teenager with cystic fibrosis}

Most young men and women with cystic fibrosis referred to our unit from recognised paediatric centres enjoy a full and active adolescence, with little if any restriction on their activities. Although presently available treatments for cystic fibrosis may be intrusive, they are effective. Employment for these young adults may be more difficult to secure and keep than for their peers, but most have been in full employment at some time. Achievements in higher education are at least as good as the national average. ${ }^{5}$ Children with cystic fibrosis should be encouraged to aim for a career that is suited to their skills. Sensible aspirations will rarely be severely compromised by physical limits imposed by their illness. It is hugely important to instil into the child and the family this sense of a real future. One often feels with adult patients that they have underachieved because they never expected to live so long so well.

The rate of decline in lung function in patients who received optimal care as children, as judged by changes in the values of the forced expiratory volume in one second $\left(\mathrm{FEV}_{1}\right)$, is almost imperceptible from one year to the next as they grow into adulthood. In contrast patients who have never been cared for in a specialist centre, or who have languished in a medical limbo since leaving their paediatric unit, will be generally in need of 'damage limitation' care. They will often respond to an intensive three pronged treatment regimen directed at nutrition, physiotherapy, and respiratory infection, enjoying a 'honeymoon period' of varying length during which respiratory function will improve. They will inevitably deteriorate relatively rapidly thereafter.

A much referenced study estimated an average life expectancy of 40 years for children with cystic fibrosis born in the 1990s and in receipt of optimal care. ${ }^{7}$ New therapeutic advances are likely to extend this prediction well into middle age. Patients who respond to rhDNase inhalations maintain an improved lung function for at least two years. ${ }^{8}$ The results of longer term and ongoing studies are needed to define the effect of rhDNase on survival and mildly affected patients. Inhalations of antiproteases may effectively reduce inflammatory attrition of lung function.' The history of scientific achievements suggests that a cure will be realised through gene therapy, although progress in this field is agonisingly slow for today's patients.

What realistically, therefore, can we tell our patients when they ask about their future? Although statistics tell us that patients with an $\mathrm{FEV}_{1}$ less than $30 \%$ of predicted normal have a $40 \%$ two year mortality, ${ }^{10}$ it is difficult to give an accurate prognosis for the individual classified as in 'the late stages' of cystic fibrosis. How much more difficult to pronounce on life expectancy for patients who are clinically stable and able to lead a normally active life. Nor do we have any data from large cohorts of older patients with liver disease associated with cystic fibrosis, which allow us to accurately judge its likely progression, with or without ursodeoxycholic acid treatment. We do know, however, that diabetes mellitus associated with cystic fibrosis can cause the same complications as classic diabetes. In all except the terminally ill we must try for reasonably tight blood glucose control, always remembering that this must not be at the expense of good nutrition, and that the management of cystic fibrosis associated diabetes mellitus allows for the necessary high energy intake.

Many young adult patients ask about fertility and the risks of pregnancy. Males are invariably sterile due to bilateral defects of the vas deferens. Biological fatherhood is possible by epididymal sperm aspiration and in vitro fertilisation, ${ }^{11}$ although the success rate of this procedure in cystic fibrosis is probably less than $20 \%$. Most women with cystic fibrosis are fertile, although abnormally thick cervical and tubal secretions, and abnormal tubal ciliary activity can be barriers to easy conception. Many factors appear to determine whether the mother will retain clinical stability after delivery, or not. Good nutritional status before and during pregnancy, and a $\mathrm{FEV}_{1}$ value greater than $60 \%$ of predicted normal before pregnancy are probably essential. ${ }^{12}$ Our own experience suggests that preconception counselling and a proper support structure after delivery for the new mother are equally as important.

\section{Conclusion}

Increasing numbers of adult patients with cystic fibrosis are requiring costly resources. Undoubtedly they can enjoy quality lives if cystic fibrosis centre paediatricians are 
involved in their early years and appropriate transfer is made to an adult clinic. A commitment to this model is needed from all paediatricians and respiratory physicians to ensure that those with cystic fibrosis have continued access to the highest standards of medical care. The 'bottom line', however, is whether hospital management is prepared to properly resource the service. Unless new staff are appointed, and beds and equipment made available, the structure of care for teenagers and adults with cystic fibrosis is likely to fragment. I believe that this will inevitably, rapidly, and irretrievably be detrimental to patients' health.

STEVEN CONWAY

Regional Adult Cystic Fibrosis Unit,

Seacroft Hospital,

Leeds LS14 $6 U$ UH

1 Clinical Standards Advisory Group. Cystic fibrosis: access to and availability of specialist services. London: HMSO, 1993.

2 Cystic Fibrosis Trust, British Paediatric Association, British Thoracic Society Working Party for Cystic Fibrosis. Clinical guidlines for cystic fibrosis care. London, 1995.
3 Royal College of Physicians. Cystic fibrosis in adults: recommendations for care of patients in the United Kingdom. London: Royal College of Physicians, 1990.

4 Southern KW, Prescott JH, Conway SP, Littlewood JM. Transfer of Care from a paediatric to an adult cystic fibrosis unit. Proceedings of the XIXth European Cystic Fibrosis Conference. Paris, 1994: 60 (abst).

5 Walters S. Association of cystic fibrosis adults (UK), survey 1994. Analysis and report.

6 British Paediatric Association Working Party on Cystic Fibrosis. Cystic fibrosis in the United Kingdom 1977-85: an improving picture. $B M \mathcal{F}$ 1988; 297: 1599-602.

7 Elborn JS, Shale DJ, Britton JR. Cystic fibrosis: current survival and population estimates to the year 2000. Thorax 1991; 46: 881-5.

8 Shah PL, Scott SF, Geddes DM, Hodson ME. Two years' experience with recombinant human Dnase $I$ in the treatment of pulmonary disease in cystic fibrosis. Respir Med 1995; 89: 449-502.

9 McElvaney NG, Hubbard RC, Birrer P, et al. Aerosol $\alpha_{1}$ antitrypsin treatment for cystic fibrosis. Lancet 1991; 337: 392-4.

10 Kerem E, Reiseman J, Corey M, Canny GJ, Levison H. Prediction of mortality in patients with cystic fibrosis. N Engl f Med 1992; 326: 1187-91.

11 Silver SJ, Ord T, Balamaceda J Patrizio P, Asch RH. Congenital absence of the vas deferens. The fertilising capacity of human epididymal sperm. $N$ Engl f Med 1993; 328: 1788-92.

12 Edenborough FP, Stableforth DE, Webb Ak, MacKenzie WE, Smith DL. The outcome of pregnancy in cystic fibrosis. Thorax 1995; 50: 170-4. 